\title{
Nano-Mechanical Modeling of Thermoelastic Behavior of AA6061/Silicon Oxide Nanoparticulate Metal Matrix Composites
}

\author{
Chennakesava R Alavala
}

Professor, Department of Mechanical Engineering, JNTUH College of Engineering, Kukatpally, Hyderabad - 500 085, Telangana, India

\begin{abstract}
The aim of the present work was to estimate non-linear thermoelastic behavior of three-phase AA6061/silicon oxide nanoparticle metal matrix composites. The RVE models were used to analyze thermo-elastic behavior using finite element analysis. The AA6061/silicon oxide metal matrix nanocomposites have lost the elastic modulus at high temperatures.
\end{abstract}

Keywords: AA6061, silicon oxide, RVE model, nano-mechanical modeling, thermoelastic, finite element analysis.

\section{Introduction}

Even though MMCs posses various advantages, they still have limitations of thermal fatigue, thermo-chemical compatibility, and posses lower transverse creep resistance [1]. Silicon carbide [2-8] and alumina [9-13] are being used as reinforcement particulates in most of the metal matrix composites. Also found in the literature about the usage of silicon nitrate, carbon and alumina trihydrate to manufacture metal matrix composites [14-16]. Fused silica is an excellent thermal insulator and has essentially zero thermal expansion. It has good chemical resistance to molten metal but is limited by its very low strength. It is used for a number of refractory and glass applications as well as for missiles. 6061 Al alloy is a precipitation hardening aluminum alloy, containing magnesium and silicon as its major alloying elements. 6061T6 aluminum is commonly used in aircraft construction. Although primarily used in private rather than commercial aircraft, its strength-to-weight ratio is very high, making it ideal for large parts that need to be very light, such as the plane's fuselage and wings. Temperature fluctuations may cause dimensional changes, because the elastic modulus is not a constant, but a function of temperature [17]. Modeling and prediction of the overall elastic-plastic response and local damage mechanisms in heterogeneous materials in general and particle-reinforced composites in particular, is a very complex problem. Finite element method (FEM) is applied to estimate the local response of the material using unit cell reinforced by a single particle subjected to periodic and symmetric boundary conditions $[18,19]$.

The significance of the present work was to evaluate the nonlinear thermoelastic behavior of $\mathrm{AA} 6061 / \mathrm{SiO}_{2}$ nanoparticulate metal matrix composites. The RVE models were used to analyze the $\mathrm{AA} 6061 / \mathrm{SiO}_{2}$ nanoparticulate metal matrix composites with interphase between them using finite element analysis.

\section{Materials and Methods}

The matrix material was AA6061 aluminum alloy. The reinforcement material was $\mathrm{SiO}_{2}$ nanoparticles of average size $100 \mathrm{~nm}$. The mechanical properties of materials used in the present work are given in table 1 . The volume fractions of $\mathrm{SiO}_{2}$ nanoparticles were $10 \%$ and $20 \%$.

Table 1: Mechanical properties of AA6061 matrix and $\mathrm{SiO}_{2}$

\begin{tabular}{|c|c|c|}
\hline Property & AA6061 & $\mathrm{SiO}_{2}$ \\
\hline Density, g/cc & 2.69 & 2.20 \\
\hline Elastic modulus, $\mathrm{GPa}$ & 68.9 & 73.1 \\
\hline Ultimate tensile strength, $\mathrm{MPa}$ & 310 & 110 \\
\hline Poisson's ratio & 0.33 & 0.17 \\
\hline CTE, $\mu \mathrm{m} / \mathrm{m}^{-{ }^{\circ} \mathrm{C}}$ & 23.6 & 0.4 \\
\hline Thermal Conductivity, W/m-K & 167.0 & 1.4 \\
\hline Specific heat, J/kg-K & 896 & 670 \\
\hline
\end{tabular}

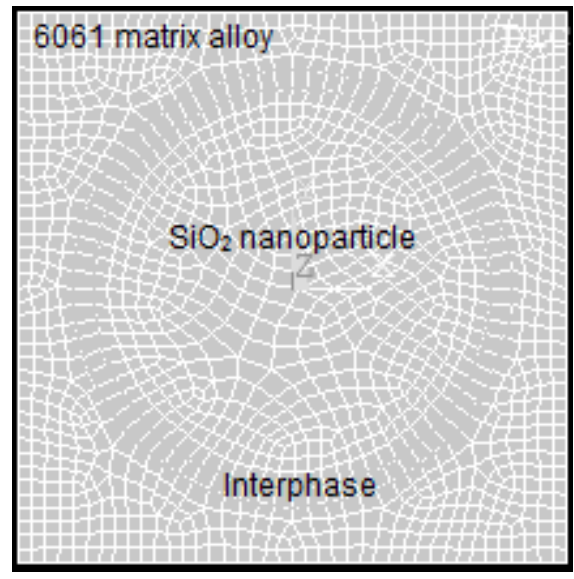

Figure 1: A square RVE containing a nanoparticle.

In this paper, a square RVE (figure 1) was executed to investigate the thermo-elastic tensile behavior AA6061/ $\mathrm{SiO}_{2}$ nanocomposites [19]. The large strain PLANE183 element was used in the matrix and the interphase regions in all the models. In order to model the interphase between nanoparticle and matrix, a CONTACT172 element was used [20]. The maximum contact friction stress of $\sigma_{y} / \sqrt{3}$ (where, $\sigma_{y}$ is the yield stress of the material being deformed) was applied at the contact surface. The basic Coulomb friction model was considered between two contacting surfaces. Both uniform thermal and hydrostatic pressure loads were applied simultaneously on the RVE model. 


\section{International Journal of Science and Research (IJSR) \\ ISSN (Online): 2319-7064}

Index Copernicus Value (2013): 6.14 | Impact Factor (2013): 4.438

\section{Results and Discussion}

The finite element analysis (FEA) was carried out at high temperature environment. The hydrostatic pressure load and uniform temperature were applied on the RVE models to examine thermo-elastic tensile behavior of AA6061/ $\mathrm{SiO}_{2}$ nanoparticulate composites. The volume fractions of $\mathrm{SiO}_{2}$ nanoparticles in the AA6061 matrix were 10\% and 20\%.

\subsection{Thermo-elastic behavior}

The influence of temperature on the elastic and thermoelastic strains is shown in figure 2. The elastic and thermoelastic strains increased with increase of temperature. For the composites having $20 \% \mathrm{SiO}_{2}$, the gradient of strain increase was higher as compared to that in the composites containing $10 \% \mathrm{SiO}_{2}$. Figure 3 exhibits the state of elastic and thermoelastic strains developed in the AA6061/ $\mathrm{SiO}_{2}$ composites. In all the cases, $\mathrm{SiO}_{2}$ nanoparticles had experienced the compressive strains in the direction normal to the tensile loading. $\mathrm{SiO}_{2}$ nanoparticles wee compressed because their CTE is lower than that of AA6061 matrix.
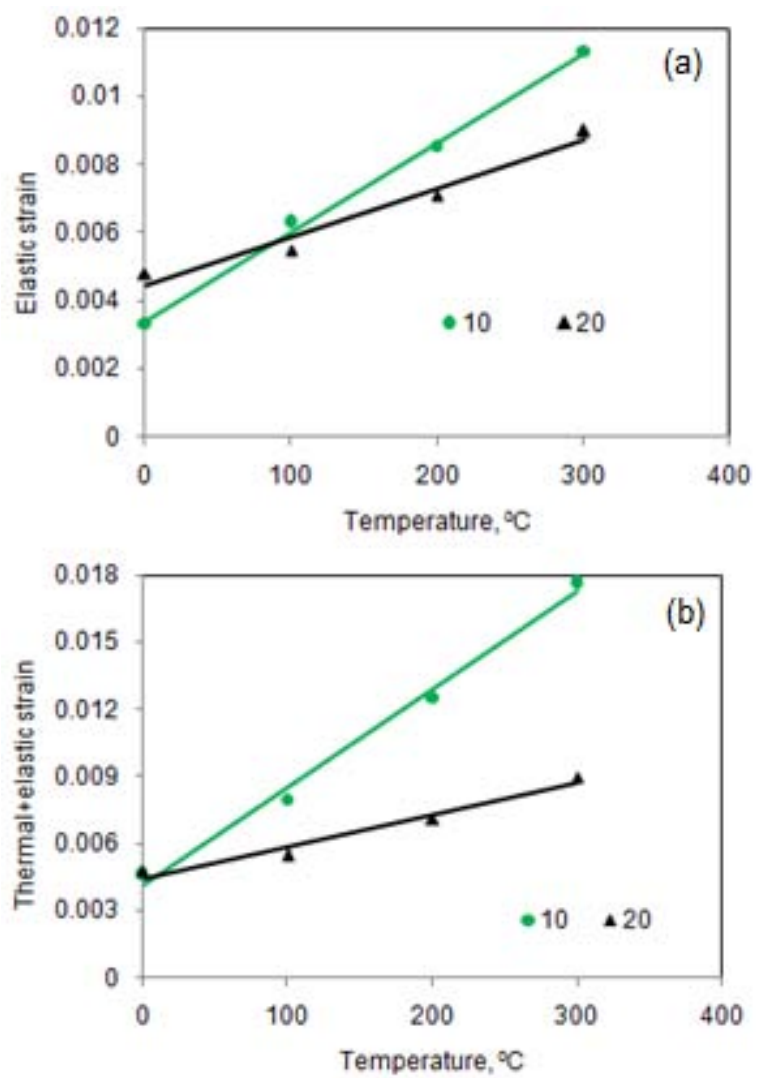

Figure 2: Influence of temperature on elastic and thermoelastic strains.

The tensile strength decreased with increase of temperature from $0^{\circ} \mathrm{C}$ to $300^{\circ} \mathrm{C}$ for both the high volume fractions of $30 \%$ $\mathrm{SiO}_{2}$ in AA6061 alloy matrix (figure 4). However, the tensile strength increased with the increase of temperature for the composites having low volume fraction of $10 \% \mathrm{SiO}_{2}$ from $0{ }^{\circ} \mathrm{C}$ to $300^{\circ} \mathrm{C}$. This might be due to the dominant role of AA6061 matrix extending the yield point and elongation. The raster images of tensile strength are shown in figure 5 for clear understanding the penalty of temperature on the tensile strength.
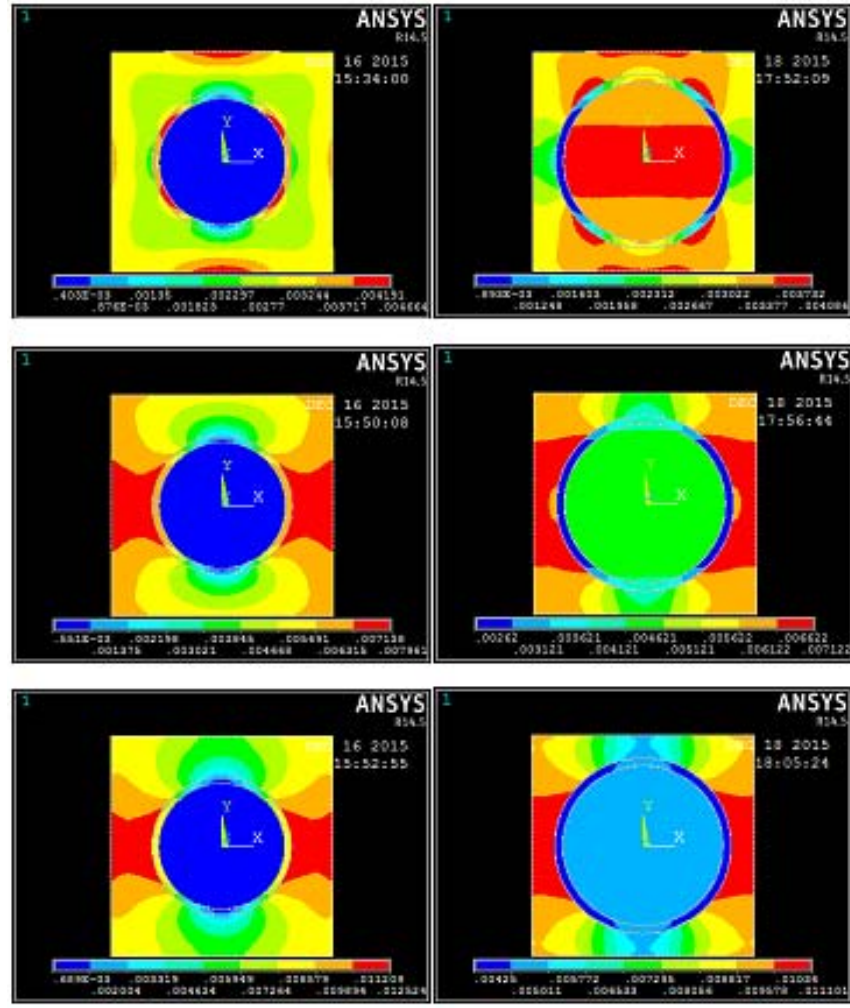

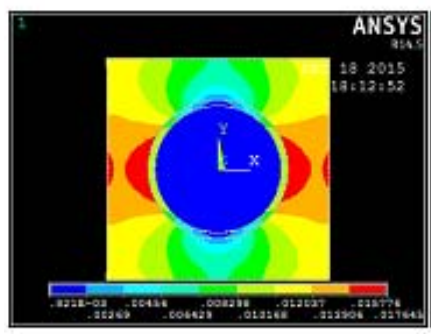

(a)

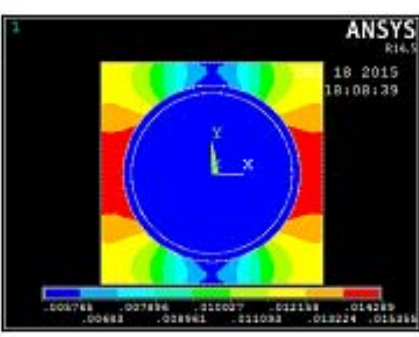

(b)
Figure 3: Thermo-elastic strains developed in composites with (a) $10 \% \mathrm{Vp}$ and (b) $\mathrm{SiO}_{2}$ nanoparticles.

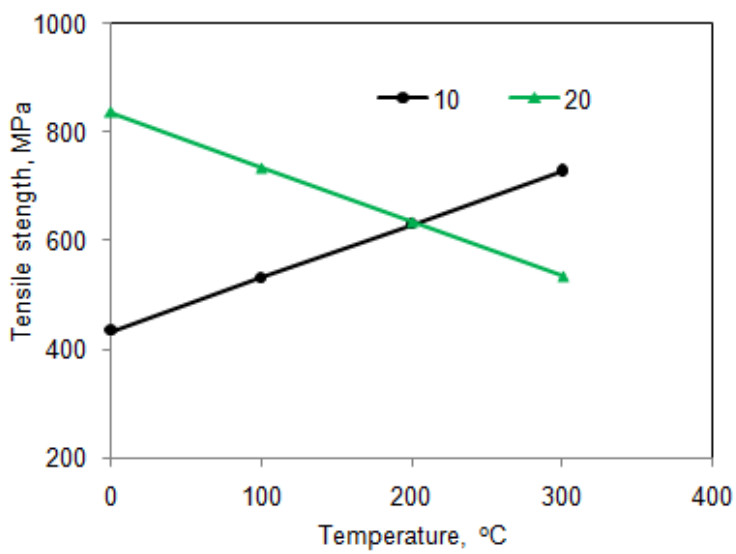

Figure 4: Effect of temperature and volume fraction of $\mathrm{SiO}_{2}$ on tensile strength.

The effect of temperature and volume fraction of $\mathrm{SiO}_{2}$ nanoparticles on elastic modulus is shown in figure 6. It was observed that the effective elastic modulus of the composite increased with higher particle volume fraction and decreased with the increase of temperature. 


\section{International Journal of Science and Research (IJSR) \\ ISSN (Online): 2319-7064}

Index Copernicus Value (2013): 6.14 | Impact Factor (2013): 4.438
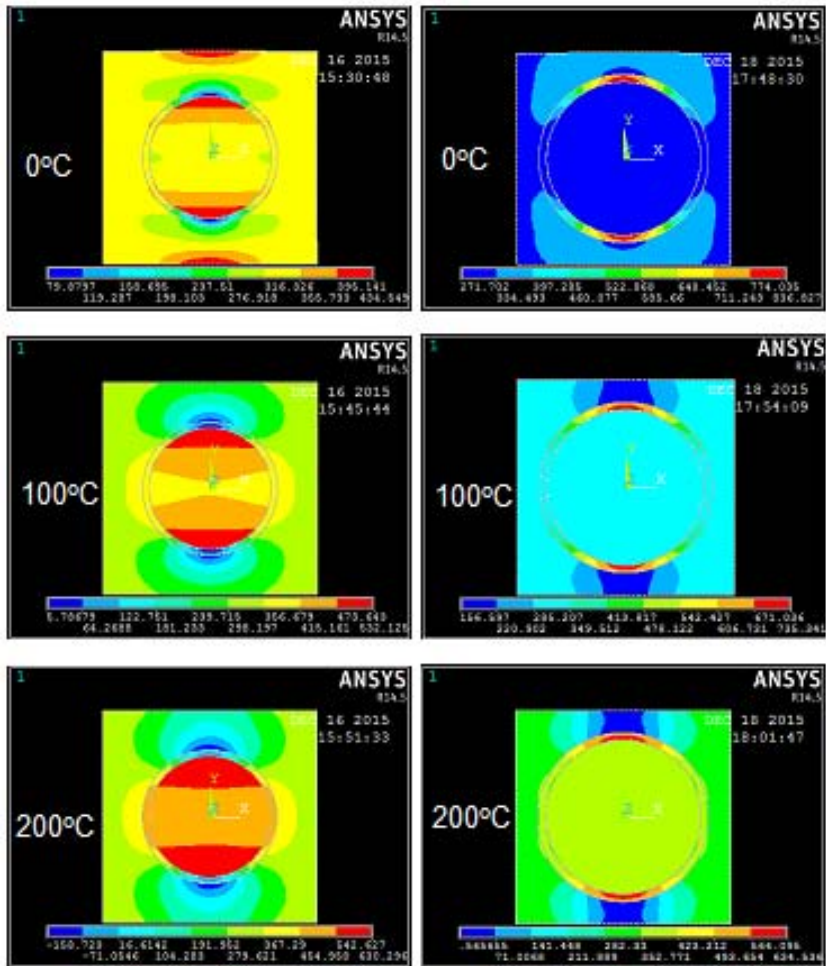

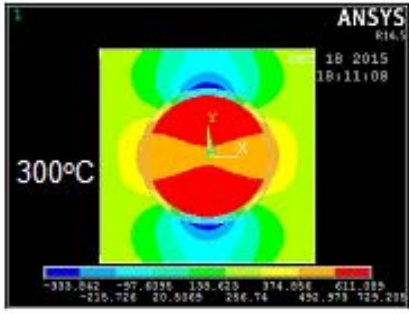

(a)

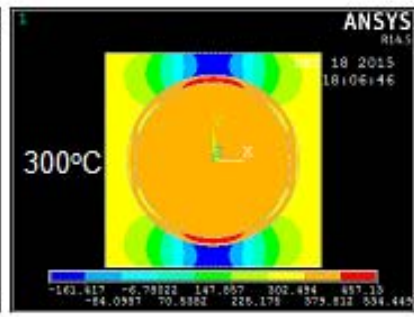

(b)
Figure 5: Tensile strength induced in composites with (a) $10 \%$ and (b) with $30 \% \mathrm{Vp}$ nanoparticles.

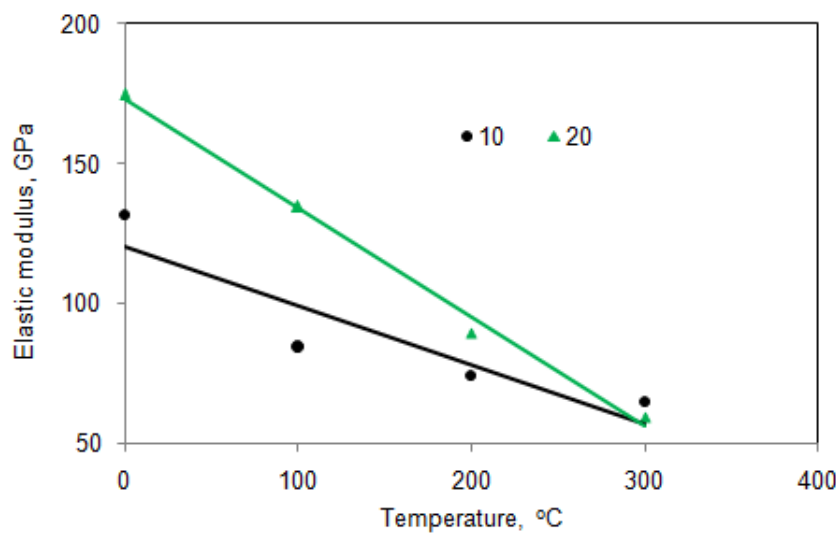

Figure 6: Effect of temperature and volume fraction of $\mathrm{SiO} 2$ nanoparticles on the elastic modulus.

\subsection{Fracture Behavior}

The von Mises stress increased with the increase of temperature increased from $0^{\circ} \mathrm{C}$ to $300^{\circ} \mathrm{C}$ (figure 7) for the composites. Within the nanoparticle various contours were also observed due to CTE mismatch between $\mathrm{SiO}_{2}$ nanoparticle and AA6061 matrix. It was also noticed that the maximum stress field in the vicinity of interphase (figure 8). This implies a potential early debonding. As the temperature increased ductile mode of failure was witnessed in the composites. Some structural changes were also locally occurred in the $\mathrm{SiO}_{2}$ nanoparticle.

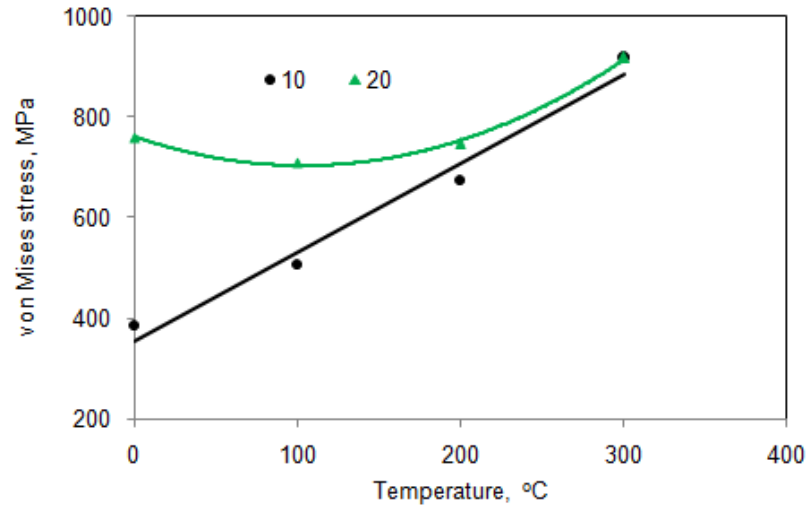

Figure 7: Effect of temperature and volume fraction of $\mathrm{SiO}_{2}$ nanoparticles the von Mises stress.
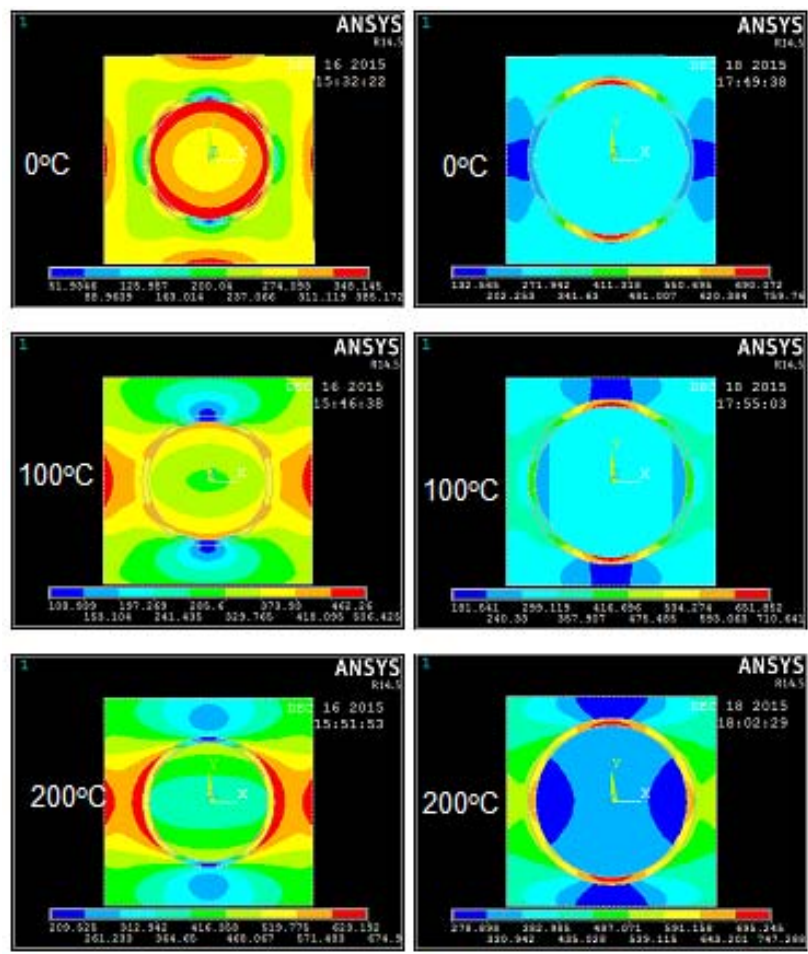

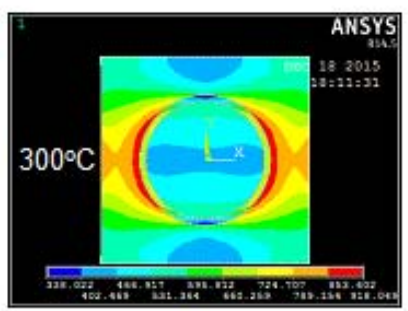

(a)

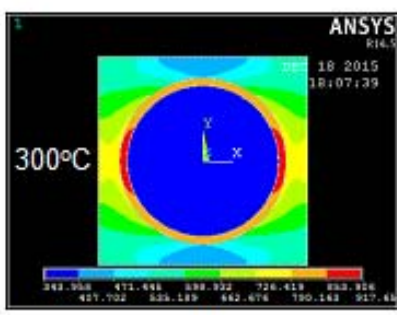

(b)
Figure 8: von Mises stress induced in composites with (a) $10 \%$ and (b) with $30 \% \mathrm{Vp}$ nanoparticles.

\section{Conclusions}

The thermo-elastic strain increased with increase in the temperature of $\mathrm{AA} 6061 / \mathrm{SiO}_{2}$ metal matrix composites. As the temperature increased, the maximum stress has occurred in the interphase region between the matrix AA6061 and $\mathrm{SiO}_{2}$. The elastic modulus of the composite decreased with high volume fraction of $\mathrm{SiO}_{2}$ and decreased with the increase of temperature.

\section{Volume 5 Issue 1, January 2016}




\section{International Journal of Science and Research (IJSR) \\ ISSN (Online): 2319-7064}

Index Copernicus Value (2013): 6.14 | Impact Factor (2013): 4.438

\section{Acknowledgement}

The author is thankful to University Grants Commission (UGC), New Delhi for sponsoring this project.

\section{References}

[1] S. Suresh, A. Mortensen, and A. Needleman, "Fundamentals of MMCs," Butterworth- Heinemann Publishing Company, Stoneham, USA, 1993.

[2] A. C. Reddy, "Evaluation of mechanical behavior of Alalloy/SiC metal matrix composites with respect to their constituents using Taguchi techniques," I-manager's Journal of Mechanical Engineering, 1(2), pp.31-41, 2011.

[3] Essa Zitoun and A.C. Reddy, "Metallurgical characteristics of fracture behavior in $\mathrm{Al} / \mathrm{SiC}$ metal matrix composite," International Conference on Advanced Materials and Manufacturing Technologies, JNTUH, Hyderabad, pp. 59-66, 18-20th December 2014.

[4] A. C. Reddy and B. Kotiveerachari, "Influence of microstructural changes caused by ageing on wear behaviour of Al6061/SiC composites," Journal of Metallurgy \& Materials Science, 53(1), pp. 31-39, 2011.

[5] T. Prasad, A. C. Reddy and S. Jushkumar, "Tensile and fracture behavior of $6061 \mathrm{Al}-\mathrm{SiCp}$ metal matrix composites," International Conference on Advanced Materials and Manufacturing Technologies, JNTUH, Hyderabad, pp.38-44, 18-20th December 2014.

[6] A. C. Reddy, "Tensile properties and fracture behavior of $6063 / \mathrm{SiC}_{\mathrm{P}}$ metal matrix composites fabricated by investment casting process," International Journal of Mechanical Engineering and Materials Sciences, 3(1), pp.73-78, 2010.

[7] P. Laxminarayana and A. C. Reddy, "Influence of heat treatment on mechanical behavior of aluminium7075/Silicon carbide composites manufactured by squeeze casting process," International Conference on Advanced Materials and Manufacturing Technologies, JNTUH, Hyderabad, pp.167-177, 18-20th December 2014.

[8] M. Geni and M. Kikuchi, "Damage Analysis of Aluminum Matrix Composite Considering Non-uniform Distribution of SiC Particles," Acta Metallurgica, 46(9), pp.3125-3133, 1998.

[9] T.S. Srivatsan, "Microstructure, tensile properties and fracture behavior of $\mathrm{Al}_{2} \mathrm{O}_{3}$ particulate-reinforced aluminum alloy metal matrix composites," Journal of Materials Science, 31(5), pp.1375-1388, 1996.

[10] A. C. Reddy, "Evaluation of mechanical behavior of Alalloy $/ \mathrm{Al}_{2} \mathrm{O}_{3}$ metal matrix composites with respect to their constituents using Taguchi," International Journal of Emerging Technologies and Applications in Engineering Technology and Sciences, 4(2), pp. 26-30, 2011.

[11]A. C. Reddy, "Strengthening mechanisms and fracture behavior of $7072 \mathrm{Al} / \mathrm{Al}_{2} \mathrm{O}_{3}$ metal matrix composites," International Journal of Engineering Science and Technology, 3(7), pp.6090-6100, 2011.

[12] R. H. Pestes, S.V. Kamat, and J.P. Hirth, "Fracture toughness of $\mathrm{Al}-4 \% \mathrm{Mg} / \mathrm{Al}_{2} \mathrm{O}_{3}$ composites," Materials Science \& Engineering, A: Structural Materials:
Properties, Microstructure and Processing, 189A, pp. 914, 1994

[13] G. Satish Babu and A. C. Reddy, "Fracture behavior of alumina particles reinforced with different matrix aluminium alloys," International Conference on Advanced Materials and Manufacturing Technologies, JNTUH, Hyderabad, pp. 67-74, 18-20th December 2014.

[14] S. Sreenivasulu and A. C. Reddy, "Thermo-mechanical properties of silicon nitrate ceramic composites for fused deposition modeling," International Conference on Advanced Materials and Manufacturing Technologies, JNTUH, Hyderabad, pp. 153-166, 18-20th December 2014.

[15] A. C. Reddy, "Analysis of the Relationship Between the Interface Structure and the Strength of CarbonAluminum Composites," NATCON-ME, Bangalore, pp.61-62, 13-14th March 2004.

[16]A. C. Reddy, "Studies on fracture behavior of brittle matrix and alumina trihydrate particulate composites," Indian Journal of Engineering \& Materials Sciences, 9(5), pp.365-368, 2003.

[17] A. C. Reddy, "Influence of strain rate and temperature on superplastic behavior of sinter forged Al6061/SiC metal matrix composites," International Journal of Engineering Research \& Technology, 4(2), pp.189-198, 2011.

[18]B. Balu Naik, A. C. Reddy and T. K. K. Reddy, "Finite element analysis of some fracture mechanisms," International Conference on Recent Advances in Material Processing Technology, Kovilpatti, pp.265270, 23-25th February 2005.

[19]H. Berger, S. Kari, U. Gabber, R.R. Rodriguez, R. Guinovart-Diaz, J. A. Otero, C. J. Bravo, "Unit cell models of piezoelectric fiber composites for numerical and analytical calculation of effective properties," Smart Material Structure, 15, pp. 451-458, 2006.

[20] C. R Alavala, "Finite Element methods: Basic Concepts and Applications," PHI Learning Pvt. Ltd., New Delhi, 2008.

Volume 5 Issue 1, January 2016

www.ijsr.net

Paper ID: NOV152708

reative Commons Attribution CC BY 